David P. Archer MD FRCPC,

Jocelyne M.A. McKenna, MD FRCPC,

Lise Morin, MD FRCPC, Patrick Ravussin MD FMH

\title{
Conscious-sedation analgesia during crani- otomy for intractable epilepsy: a review of 354 consecutive cases
}

The perioperative records of 354 conseculve patiens under. going craniatomy for surgical treatment of intractable epilepsy performed with conscious-sedation analgesia were reviewed retrospectively. There was no perioperative morbidity or mortality identified which could be attributed to the anaesthetic technique. The technique was not switable for seven patients, in whom general anaesthesia was induced. The most frequent intraoperative problems were convulsions (16 per cent) and nausea and vamiting (eight per cent). Less frequent problems included excessive sedation (three per cent), "tight brain" (1.4 per cent) and local anaesthetic toxicity ( $t$ wo per cent). This study confirms that conscious-sedation analgesia provides suitable conditions for cruniotomies when brain mapping is required.

Despite recent advances in electrophysiologic monitoring, intraoperative cortical mapping in the awake patient remains an important surgical adjunct for patients whose pathology is located near motor, language, or memory areas of the brain. 'This method has been used extensively for the surgical treatment of complex-partial seizures. ${ }^{2.3}$ Partial (focal) seizures begin with a localized discharge during which consciousness may remain intact (simple partial seizure) or become impaired (complex-partial scizure) ${ }^{4}$ The location of the epileptogenic focus determines the initial clinical manifestations of the seizure. Electroencephalographically, partial epilepsy is associ-

\section{Key words}

ANAEST HESIA: intravenous, neuroleptanalgesia; SURGERY: neurosurgery, epilepsy.

From the Department of Neuroanaesthesia, Montreal Neurological Institute and Hospital, McGill University, Montreal, Quebec.

Address correspondence to: Dr. Dayid P. Archer, Department of Anaesthesia, Foothills Hospital, 1403-29 Street N.W., Calgary, Alberta, T2N 2T9. ated with focal paroxysmal depolarizations in one or more groups of neurons. The majority of surgical candidates at the Montreal Neurological Hospital have a focus located in the anterior temporal lobe or frontal lobe. In epileptic patients the locations of the speech centres are highly variable, ${ }^{5}$ hence the value of individualizing the extent of resection for each patient. In most patients the seizure focus is associated with localized gliosis secandary to birth of postnatal trauma, postinflammatory brain scarring or of unknown aetiology. In some patients a small tumour or arteriovenous malformation may be present, while in others no pathology is apparent. In patients without seizures, the cortical mapping technique may be readily applied to selected individuals with neoplasms or arteriovenous malformations involving eloquent brain regions. Using cortical mapping to identify functional brain regions, the surgeon may resect lesions that would be considered inoperable on the basis of the classical cortical representation of speech

Conscious-sedation analgesia during cortical mapping and resection for treatment of medically intractable epilepsy has been the standard clinical practice at the Montreal Neurological Institute and Hospital for more than fifty years. This practice has recently been described in detail. ${ }^{6}$ Briefly, the unpremedicated patient is lightly sedated with droperidol and fentanyl and placed in the lateral position. Vital signs are monitored with a continuous display of the ECG, a thoracic impedance respiratory tracing and intermittent non-invasive blood pressure determinations. A urinary catheter is not routinely inscrted. As a recent addition, oxygenation is monitored with transcutaneous $\mathrm{PO}_{2}\left(\mathrm{P}_{\mathrm{tc}} \mathrm{O}_{2}\right)$ measurements or pulse oximetry. The surgical drapes are applied so that the anaesthetist has adequate access to the patient's airway and so that the patient's view of the anaesthetist is unimpaired. Oxygen ( $3 \mathrm{~L} \cdot \mathrm{min}^{-1}$ ) is supplied under the surgical drapes in the region of the patient's face. The surgeon then infiltrates the scalp ${ }^{2}$ with dibucaine 0.67 per cent $(125 \mathrm{ml})$ and 0.25 per cent ( $125 \mathrm{ml}$ ) with 1:200,000 epinephrine. During the opening of the bone flap, additional infiltration is pro- 
vided for the middle meningeal artery and for the dura if necessary. Supplements of fentanyl are kept to a minimum in order that the patient may maintain normal respiration, conserve airway reflexes and be alert during cortical mapping and electroencephalography. Methohexitone $\left(0.5 \mathrm{mg} \cdot \mathrm{kg}^{-1}\right)$ may be requestcd by the electroencephalographer in an attempt to stimulate the epileptogenic focus. ${ }^{7}$ Following cortical mapping, resection of the epileptic focus is carried out. After a second electrocorticogram has confirmed removal of the focus, the craniotomy is closed.

Although this technique enables the surgical team to perform precise functional mapping of the cortex, it exposes the patient to several potential hazards which are of concern to the anaesthetist. The most serious problems are tonic-clonic convulsions and dysphoric reactions, both of which may lead to loss of control of a paticnt with an open craniotomy. Respiratory depression due to seizures or medications may occur and in the unintubated patient treatment of the subsequent brain engorgement may be difficult. Nausea and vomiting may occur, particularly in association with dissection and traction on the dura on the floor of the temporal fossa. Aspiration is consequently a possibility.

Despite these potential difficulties, few major problems are encountered - in a review of over 1000 patients with nontumoural epileptogenic lesions treated surgically at the $\mathrm{MNH}$, Rasmussen reported no mortality or mobidity which was related to the anaesthetic technique. ${ }^{8}$ To date studies have not examined intraoperative problems during "awake" craniotomy. The purpose of this study was to examine retrospectively the medical records of patients who had undergone surgery for intractable epilepsy with "awake" craniotony in order to evaluate the nature and frequency of problems encountered intraoperatively by the anaesthetist.

\section{Methods}

Institutional approval for confidential record review was obtained from the Montreal Neurological Hospital.

The medical records of 358 consecutive patients (1976-1983) who underwent cortical resections for the treatment of intractable epilepsy performed under conscious-sedation analgesia were reviewed retrospectively by one of three anaesthetists. In these patients small tumours or arteriovenous malformations associated with the seizure focus were incidental findings. The patients were therefore not grouped according to aetiology. Particular artention was paid to the anaesthetic record and the operative report to document the duration of the operation, the medications used and any problems encountered by the anaesthetist or the surgeon. Specifically, evidence was sought in the anaesthetic record and in the operative report for seizures, nausea/voniting/aspiration, local anaesthetic toxicity (convulsions temporally related to infiltration), poor patient cooperation, excessive sedation, inadequate neurosurgical conditions (brain swelling) and loss of control by the patient. Excessively sedated patients were those who were noted in the operative note to be difficult to evaluate during stimulation and those who received antagonists (naloxone/physostigmine) during the procedure. The postoperative notes and discharge summary were reviewed to determine whether any anaesthetic related morbidity became evident postoperatively.

In a separate study, continuous transcutaneous oxygen $\left(\mathrm{P}_{\mathrm{rc}} \mathrm{O}_{2}\right)$ measurement was performed in 11 paticnts as part of their intraoperative monitoring, using a Kontron Mode] 632 electrode system (Kontron Ltd, Munchenstein, Switzerland) which was equipped with a strip chart recorder. The electrode temperature was $42^{\circ} \mathrm{C}$ and it was calibrated to air at the barometric measure of the room. Electrodc recalibration to air was performed every four hours when the electrode position was changed. These data were reviewed in order to determine whether there were any clinically unsuspected episodes of decreased oxygen delivery intraoperatively. The $\mathrm{P}_{t c} \mathrm{O}_{2}$ tracings were normalized by calculating the ratio of the transcutaneous $\mathrm{PO}_{2}$ measurement after equilibration to the oxygen tension in an arterial sample $\left(\mathrm{PaO}_{2}\right)$ determined simultaneously. Each tracing was analyzed to determine the lowest value of $\mathrm{P}_{1 \mathrm{c}} \mathrm{O}_{2}$.

Statistical analysis of the abstracted patient records was performed with a personal computer (IBM ${ }^{3}$ PC) spreadsheet program (Lotus 1-2-3 ${ }^{\circ}$, Lotus Development Corp, Cambridge, Mass.). For parametric variables (age, weight, dose $/ \mathrm{kg}$ body weight of fentanyl and duration of surgery) the frequency distribution of the variable in the population was constructed and compared to the normal distribution. This was done by computing the percentile points of the population and comparing these with the values predicted from the mean and standard deviation of the population. The percentile points used were: $2.5,16$, 50,84 , and 97.5 . Comparison was made with the appropriate values predicted from the mean, and mean + $I$ and 2 standard deviations. The distribution was considered to be normal if the comparison agreed within five per cent. Skewed distributions were summarized by the median and 25,75 percentile values. ${ }^{9}$

\section{Results}

The study population

From April 1976 to November 1983 there were 358 craniotomies for cortical resection for epilepsy performed under conscious-sedation analgesia at the Montreal Neurological Hospital. Medical records could not be located 
TABLE I Summary of study population statistics (341 patients, 181 females, 160 males)

\begin{tabular}{lllll}
\hline & \multicolumn{4}{c}{ Percentiles } \\
\cline { 3 - 4 } & Median & 25 & 75 & Range \\
\hline Age in years & 24 & 19 & 30 & $12-75$ \\
Body weight $(\mathrm{kg})^{*}$ & 65 & 56 & 77 & $40-120$ \\
\hline
\end{tabular}

*Weight data available for $276 / 341$ patients

for four patients. The remaining 354 procedures are the subject of this report. For seven patients general anaesthesia had to be induced at an early stage in the procedure. Although these patients appear in the "Intraoperative problems" section below, numerical values for these individuals were not included for the purpose of statistical evaluation. Thus the review covered 347 operative procedures.

Since six patients (four males, two females) were reoperated during the study period, the group was composed of 341 separate individuals - 181 females and 160 males. The age and weight data for the population are summarized in Table I.

Excluding their seizure disorder, all patients were ASA physical status class I or II except for one 75-year-oid male patient with lung cancer metastatic to the temporal lobe.

The duration of surgery (from arrival in the OR suite until transfer to the recovery area) ranged from $390-850$ minutes, with a mean duration of 578 minutes or 9.5 hours.

Dosages of intravenous anaesthetic agents (Table II) All patients received fentanyl (total cose range 300-1760 $\mu \mathrm{g}, 1-24 \mu \mathrm{g} \cdot \mathrm{kg}^{-1}$ ) during the procedure. Note that weight data were not available for all patients; the patient who received $1760 \mu \mathrm{g}$ likely exceeded $24 \mu \mathrm{g} \cdot \mathrm{kg}^{-1}$. The total dose/weight distribution, calculated for the 274 patients for whom weight data was available, is shown in the Figure.

Droperidol was given to all except three patients. Since droperidol was routinely given to this type of patient, and since none of the three individuals had a recorded

TABLE II Total doses of anaesthetic medicatians

\begin{tabular}{lrrrr}
\hline & \multicolumn{4}{l}{ Percentiles } \\
\cline { 3 - 5 } & Median & 25 & 75 & Range \\
\hline Fentanyl $\left(\mu \mathrm{g} \cdot \mathrm{kg}^{-1}\right) *$ & 6 & 5 & 8.5 & $1-24$ \\
Droperidol $(\mathrm{mg})$ & 10 & 5 & 15 & $0-40$ \\
Methohexitone $(\mathrm{mg})$ & 150 & 80 & 270 & $0-890$ \\
\hline
\end{tabular}

* Weight data available for $276 / 341$ patients.



FIGURE Frequency distribution of total fentanyl dose/body' weight in the 276 patients for whom weight data was available. The median dose was $6.0 \mu \mathrm{g} \cdot \mathrm{kg}^{-1}$.

contraindication to the drug, there was likely a recording error in these three patients. The maximum initial dose of droperidol was $20 \mathrm{mg}$ - total doses of 30,35 , and $40 \mathrm{mg}$ represent supplemental drug administration during closure following long craniotomies.

The majority of patients received methohexitone in a bolus dose of $40 \mathrm{mg}$ intravenously to stimulate the cortical activity. Some patients also reccived methohexitone for sedation or control of convulsions. Twenty-nine patients did not receive methohexitone.

During closure of the craniotomy 42 per cent of patients (148/347) were given other sedative medications for comfort. Diazepam in total doses from 2.5 to $50 \mathrm{mg}$ was the most frequently used sedative (134 patients). In the most recent cases in the series lorazepam was used (six patients) in doses from 0.6 to $4 \mathrm{mg}$. Eight patients were sedated with infusions without tracheal intubation (alphathesin in five cases, methohexitone in three cases).

\section{Intraoperative problems}

Seven patients could not cooperate sufficiently for surgery to be performed and in all seven general anaesthesia was induced with thiopentone or methohexitone and maintained using a balanced technique with nitrous oxide 66 per cent in oxygen, a nondepolarizing muscle relaxant, and supplemental doses of fentanyl as necessary. Tracheal intubation was performed in the lateral position with the surgical drapes removed from around the face to facilitate access to the head. A radial arterial cannula and a peripheral nerve stimulator were added to the basic monitoring.

The characteristics of these seven patients are shown in Table III. Prior to skin infiltration, three patients were unsuitable for conscious-sedation analgesia following sedation and positioning - one patient was uncooperative, one was belligerent on the basis of an underlying 
TABLE III Paticnts requiring conversion to general anaesthesia (seven parients, all males)

\begin{tabular}{|c|c|c|c|c|c|}
\hline \multirow[b]{2}{*}{ Patient } & \multirow[b]{2}{*}{ Age } & \multicolumn{3}{|c|}{ Medications prior to $G A$} & \multirow[b]{2}{*}{ Comment } \\
\hline & & $\begin{array}{l}\text { Fentanyl } \\
(\mu g)\end{array}$ & $\begin{array}{l}\text { Droperidol } \\
\text { (mgl }\end{array}$ & $\begin{array}{l}M H X T \\
(m g)\end{array}$ & \\
\hline 1 & 17 & - & - & - & Uncooperative \\
\hline 2 & 22 & 80 & 15 & - & Belligerant. ?Dysphoric \\
\hline 3 & 18 & 100 & 15 & - & Partial complex scizure prior to infiltration \\
\hline 4 & 23 & 220 & 15 & 290 & Did not tolerate incision \\
\hline 5 & 18 & 250 & 5 & 180 & Uncooperative following seizure \\
\hline 6 & 39 & 300 & 10 & 160 & Bitrontal brain injury \\
\hline 7 & 19 & 240 & 15 & 285 & ?Dyspharic reaction \\
\hline
\end{tabular}

personality disorder and the other had four complexpartial seizures during positioning. Following a period of observation in the induction room, general anaesthesia was induced in each and the surgery proceeded uneventfully. The remaining four patients became uncooperative during the surgical procedure. In one parient, the infiltration of local anaesthetic was inadequate and he reacted violently to the skin incision. Two patients became uncooperative following the skin incision. One of these patients, with traumatic bifrontal brain damage and a history of behavioural problems, may have been poorly selected for the procedure to be done "awake." The other patient, following a generalized seizure during infiltration, became restless during the turning of the skin flap, and it was judged prudent to induce general anaesthesia before the bone flap had been opened. The final patient in this group became very uncooperative during the turning of the bone flap. He had not been observed to have a seizure, but had been anxious and uncooperative during infiltration. Following the turning of the skin flap, he attempted to sit up, requiring the infuction of general anaesthesia.

In all of the above cases the epileptic focus was located by intraoperative electrocorticography and a suitable, if sometimes more conservative, resection was performed in all cases. There were no postoperative wound infections in this group, a complication which might be feared considering that some of the patients were intubated under the drapes with the surgical incision open.

Fifty-five patients had intraoperative seizures which were not attributable to local anaesthetic toxicity (Table IV). Postictally, six became significantly uncooperative and confused. Of these, (wo required induction of general anaesthesia in order to proceed with the operation. (These latter two patients were mentioned above.) The onset of the seizure was associated with cortical or depth electrode stimulation in 28 of the 55 patients with seizures. No patient aspirated during a seizure, and none of the patients progressed to tonic-clonic status epilepticus.

Nausea and vomiting were recorded during 27 proce-
TABLE IV Summary of intranperative problems

\begin{tabular}{ll}
\hline Problem & Frequency $(\%)$ \\
\hline Sejzures & 16 \\
Nausea'vomiting & 8 \\
Excessive sedation & 3 \\
Change to GA required & 2 \\
"Tighr" brain & 1.4 \\
Local amaesthetic toxicity & 2 \\
\hline
\end{tabular}

dures. No patient showed signs of an acute aspiration syndrome and only one patient developed postoperative pneumonia, an elderly man with chronic obstructive lung disease and previous thoracotomy for lung cancer. This patient was not noted to have become nauseated or vomited during the procedure. The patient may become nauscated at any time during the procedure, the highest incidence occurring during dissection along the medial aspect of the floor of the temporal fossa. Although the patients were fasting, the volume of vomited material was frequently in excess of $500 \mathrm{ml}$. Patients were most commonly treated with perchlorperazine $5-10 \mathrm{mg}$ IM or droperidol $2.5-5 \mathrm{mg}$ IV.

In five patients the brain was sufficiently "tight" to interfere with dural opening and therefore prompt treatment with furosemide, mannitol, lidocaine or by requesting the patient to hyperventilate prior to dural opening. Blacder catheterization was not performed if a diuretic was used - a urinal was provided. The total dosages of fentanyl and methohexitone for these patients were not greater than the average; the rate of administration of these drugs during the early part of the case was unfortunately not available. Only one patient in this group was felt to be oversedated and was treated with physostigmine. In one of the two patients to whom lidocaine 1.0 $\mathrm{mg} \cdot \mathrm{kg}^{-1}$ was administered to reduce brain bulk, a tonic-clonie seizure followed. In all of these patients dural opening was successfully accomplished and no further problems with brain bulk were encountered. No patient developed brain swelling after dural opening. 
Seven patients developed signs compatible with local anaesthetic or epinephrine toxicity during of shortly after scalp infiltration. One patient had sinus tachycardia $\left(130-140\right.$ beats $\left.\cdot \min ^{-1}\right)$ which began during infiltration and lasted one hour. Five patients had convulsions, three of these partial complex, two tonic-clonic. All were rapidly treated with small doses of methohexitone. In one of the two patients with tonic-clonic seizures, post-ictal confusion required induction of general anaesthesia in order to proceed with surgery. One patient developed tachycardia and severe shivering, both of which responded to methohexitone $260 \mathrm{mg}$ given in divided doses over the 30 minutes following infiltration of the scalp.

Excessive sedation, sufficient to interfere with patient evaluation during stimulation or requiring antagonism with naloxone or physostigmine ${ }^{10}$ was noted during 11 procedures. In three cases, the opening had been somewhat difficult requiring larger doses than usual of fentanyl and/or methohexitone. In the remaining eight cases, the total doses of intravenous sedatives, hypnotics, and narcotics were not unusual. Antagonists were administered to five of the 11 patients. Physostigmine was administered to two patients, physostigmine and naloxone to one patient and naloxone alone to two patients. No dysphoric reactions, pulmonary oedema or loss of patient control were recorded among the patients to whom antagonists were given.

\section{Intraoperative oxygenation}

Once the surgical drapes were applied the introduction of $3 \mathrm{~L} \cdot \mathrm{min}^{-1}$ of oxygen near the patient's face yielded an $\mathrm{FIO}_{2}$ of $0.27-0.35$ as measured by a polarographic oxygen analyzer. The $\mathrm{P}_{\mathrm{tc}} \mathrm{O}_{2}$ data, summarized in Table $\mathrm{V}$, demonstrate that in these uncomplicated cases there were no intraoperative episodes of decreased oxygen delivery.

\section{Discussion}

Some limitations were imposed by the retrospective design of the study - desirable information was not always available in the patient record and the lack of a standard anaesthetic protacol made interpretation of results difficult. Specifically, the haemodynamic effects of the scalp infiltration could not be characterized because measurements were not made according to a schedule and the volume of dibucaine/epinephrine injected was not recorded. The type, duration and cardiorespiratory effects of intraoperative seizures were not commonly documented in the patient record. This was because the patient frequently recieved methohexitone as soon as the presence of the seizure was diagnosed in order to prevent it from becoming generalized, since the impact of a
TABLE $\mathrm{V}$ Results of $\mathrm{P}_{\mathrm{tc}} \mathrm{O}_{2}$ monitoring

\begin{tabular}{rlrr}
\hline & \multicolumn{3}{c}{ Lowest $P_{x c} O_{2}$} \\
\cline { 3 - 4 } Patient & $P_{4 c} \mathrm{O}_{2} / \mathrm{PaO}_{2}$ & $\mathrm{mmHg}$ & $\mathrm{kPa}$ \\
\hline 1 & 0.67 & 74 & 9.5 \\
2 & 0.87 & 106 & 13.8 \\
3 & 0.77 & 84 & 11.1 \\
4 & 0.94 & 75 & 9.9 \\
5 & 1.00 & 82 & 10.8 \\
6 & 0.96 & 124 & 16.3 \\
7 & 0.90 & 92 & 12.1 \\
8 & 0.85 & 79 & 10.4 \\
9 & 0.89 & 86 & 11.3 \\
10 & 0.79 & 70 & 9.2 \\
11 & 0.86 & 100 & 13.3 \\
\hline
\end{tabular}

complex-partial seizure on respiration, acid-base balance and cardiovascular stability is much less than that of a generalized seizure. This study has tried to document the frequency of major management problems; there may be effects of this anaesthetic technique which could be hazardous to selected paticnts (e.g.s, epinephrine-related tachycardia in patients with ischaemic heart disease) which have not been addressed by this study.

This study confirms the clinical experience ${ }^{6}$ that conscious-sedation analgesia can provide reasonable conditions for cortical mapping and resection of epileptogenic foci. The most serious problems which were encountered in this series of 354 procedures concemed the seven patients (twa per cent) in whom general anaesthesid had to be induced. Although this was accomplished without incident in these cases, this situation is not to be taken lightly as airway control can be exceedingly difficult.

Seizures were observed frequently in this series ( 16 per cent of cascs). This is to be expected in a group of epileptic patients in whom anticonvulsants have been witheld preoperatively for at least 12 hours in order to improve localization of seizure foci on the electrocorticogram. Electrical stimulation of the cortical or depth electrodes during cortical mapping was a potent stimulus for seizures, since in $28 / 55$ cases ( 51 per cent) the onset of seizures coincided with stimulation. Although none of the patients progressed to status epilepticus intraoperatively, two patients were given gencral anaesthesia because of seizures, one for frequent preoperative seizures and one for post-icital confusion. Six other patients were noted to be uncooperative post-ictally, but were controllable.

Although nausea and vomiting were observed in eight per cent of patients, clinically significant aspiration did not occur. This implies that the highest frequency of aspiration to be anticipated for this procedurc is approximately one per cent. ${ }^{16}$ Pulmonary aspiration has not been 
reported as a cause of morbidity or mortality in an unselected series of over 2000 cases of seizure surgery reported from this institution. ${ }^{8}$

Excessive sedation and brain engorgement were not common problems, occurring in ten (three per cent) and five ( 1.5 per cent) patients respectively. In fact, brain engorgement was considered to be related to excessive sedation in only one patient. It is important to note that the patients in the present study did not have pathology which was associated with significant brain swelling or oedema. It is likely that more difficulties with brain engorgement would be encountered more frequently if the conscioussedation analgesia technique was applicd to patients with such pathology.

The results of this study suggest that the dose of dibucaine used for these paticnts was not associated with a significant increase in seizures. Even in this group of patients with a low seizure threshold, in whom anticonvulsants have been routinely witheld there were only five seizures following the infiltration (1.2 per cent), and of these three were partial complex while two were tonicclonic. One patient was sufficiently confused following a major motor seizure that general anaesthesia had to be induced in order to proceed with the surgery (see Conversion to general anaesthesia above). The two other systemic reactions observed were tachycarcia and shivering seen in one patient each. The operative records did not include information concerning early signs of CNS toxicity such as tinnitus and circumonal numbness.

Dibucaine has been used in this setting because of its long duration of action. A maximum dose of dibucaine with epinephrine for scalp infiltration has not been reported, nor has the correlation between serum levels of dibucaine and clinical side effects. Maximum doses from $40 \mathrm{mg}^{12}$ to $2 \mathrm{mg} \cdot \mathrm{kg}^{-111.12}$ have been recommended for infiltration in general. At the MNH over the past 30 years the protocol for infiltration has provided the surgeon with $100 \mathrm{mg}$ of dibucaine. Of this, $75 \mathrm{mg}$ was provided at a concentration of $0.66 \mathrm{mg} \cdot \mathrm{ml}^{-1}$ while the remainder was in a concentration of $0.16 \mathrm{mg} \cdot \mathrm{kg}^{-1}$. If all of the dibucaine was injected (which it rarely is) then the median dose body weight for this series would be $1.6 \mathrm{mg} \cdot \mathrm{kg}^{-1}$ with a range of $0.83-2.5 \mathrm{mg} \cdot \mathrm{kg}^{-1}$. The dose of local anaesthetic used for infiltration was not part of the patient record and therefore average doses are not available. The subcutaneous dose of epinephrine can be up to $1 \mathrm{mg}$, administered over 20 minutes. This dose is in the same range as that used therapeutically for asthma in adults. ${ }^{14}$

In the 11 patients studied with transcutaneous oxygen measurements $\mathrm{P}_{\mathrm{tc}} \mathrm{O}_{2}$ was well maintained throughout the operative period. Since none of these patients had prolonged seizures of excessive sedation, hypoxacmia would not have been expected on clinical grounds. Although transcutaneous monitoring may be unreliable for evaluating $\mathrm{PaO}_{2}$ in adults ${ }^{\mathrm{I}}$ some authorities feel that the $\mathrm{P}_{t c} \mathrm{O}_{2}$ is a reliable index of oxygen delivery. ${ }^{15}$ The continuous recordings do confirm that decreases in oxygen delivery were not as common during the intraoperative period.

\section{Summary and Conclusions}

Conscious-sedation analgesia is a technique which allows the surgeon to perform intraoperative cortical mapping for brain regions which can not at present be evaluated by electrophysiologic means (e.g., evoked potentials). This anaesthetic technique was not associated with significant morbidity or mortality in the 354 consecutive cases reviewed.

Although the doses of neuroleptic drugs varied widely and in some cases were quite large, it is a general principle that intravenous medication should be kept to a minimum. It is recommended that specific training during "awake" craniotomy by both the surgical and anaesthetic team is useful to familiarize team members with the problems associated with the technique. Specifically, patients occasionally move, complain of pain, convulse or vomit. Practice is required by the surgeon to become adept at the regional anaesthesia technique upon which the surgical exposure depends. The surgeon and the anaesthetist need to develop a "bedside" manner for these patients. By becoming familiar with these problems, the operating tcam can avoid excessive doses of sedatives which may be administered in attempts to reproduce the conditions obtained with general anaesthesia.

\section{Acknowledgement}

The authors thank Dr. Davy Trop for his constructive criticism during the study and during the preparation of the manuscript.

\section{References}

1 Black PMcL, Ronner SF. Cortical mapping for defining the limits of tumor resection. Neurosurgery 1986; 20 914-9.

2 Penfield $W$, Pasquet $A$. Combined regional and general anaesthesia for craniotomy and cortical exploration. Anaesth Analg 1954; 33: 145-64

3 Dreifuss $F E$. Goals of surgery for epilepsy. In: Surgical treatment of the epilepsies. Engel J (Ed). Raven Press, New York 1987: pp. 31-50.

4 Schomer DL. Partial Epilepsy. N Engl J Med 1983; 309 536-9.

5 Ojemann $G A$. Individual variability in cortical localization of language. J Neurosurg 1979; 50: 164-9. 
6 Trop D. Conscious-sedation analgesia during the neurosurgical treatment of epilepsies - practice at the Montreal Neurological Institute. In: Anesthetic Considerations for Craniotomy in Awake Patients. Varkey G (Ed). International Anesthesiology Clinics, No. 3. Little, Brown and Company, Boston 1986, pp. 175-84.

7 Wilder BJ, Muselta $L_{t}$ Van Horn $G$, Schmidt RP. Activation of spike and wave discharge in patients with generalized seizures. Neurology 1971; 21:517-27.

8 Rosmussen, TB. Surgical treatment of complex-partial seizures: results, lessons, and problems. Epilepsia 1983; 24: $565-\$ 76$.

9 Glantz SA. Primer of biostatistics. McGraw-Hill Book Co., New York 1981: p. 17.

10 Thompson DEA. Physostigmine as an adjuvent to neuroleptanalgesia in neurosurgical procedures. Can Anaesth Soc J 1976; 23: 582-6.

11 Moore $D C$. Regional Block. 5th Ed. Charles Thomas, Springfield 1969, p. 14.

12 Atkinson RS, Rushman GB, Lee JA. A Synopsis of Anaesthesia. 8th Ed. John Wright \& Sons, Bristol 1976, p. 360 .

13 Knill RL, Clement $J L$, Kierazewiecs $H T$, Dodgson $B G$. Assessment of two noninvasive monitors of arterial oxygcnation in anesthetized man. Anesth Analg 1982; 61: 582-6.

14 Wilkins EW (Ed). Textbook of Emergency Medicine. Williams and Wilkins, Baltimore 1983, p. 163.

15 Shoemaker WC, Tremper KK. Transcutaneous $\mathrm{PO}_{2}$ and $\mathrm{PCO}_{2}$ monitoring in the adult. In Textbook of Critical Care. Shoemaker WC, Thompson WL, Holbrook PR (Eds). WB Saunders Co., Philadelphia 1984, pp. $176-81$.

16 Hanley $J A$, Lippman-Hand A. If nothing goes wrong, is everything all right? Interpreting zero numerators. JAMA 1983; 249: 1743-5.
Résumé

Nous avons revisé les dossiers de 354 patients ayant subi une craniotomie pour exérese de tissue épileptogenique. L'anesthésie employée esi une technigue de sédation et d'anaigésie. Une étudie rétrospective a eté entreprise pour identifier les complications antesthésiques. It n'y a pas eu de mortalité ou de morbidité secondaire d̀ la technique d'anesthésie. Sept parients n'ont pas toléré l'intervention et l'induction d'anesthésie genérale à été nécessaire chez ces patients. Les problèmes per-opératoires les plus fréquents ont été les comvulsions (16 pour cent), les nausées et les vomissements (huit pour cent). Moins fréquemment, sont survenus de la sédation excessive (trois pour cent), de l'engorgement du cerveau (un pour cent), et des réactions toxiques da l'anesthésique local (un pour cent). Le monitorage de ta pression d'oxygène transcutanée chez 11 patients sans complications per-opérotoires n'd révélé aucun hypoxie durant les intenventions. 